\title{
The Investigation and Evaluation of Service Performance of Warm Mix Asphalt Modifier
}

\author{
Ping $\mathrm{Wu}^{\mathrm{a}}{ }^{*}$, Tianyu $\mathrm{Li}^{\mathrm{b}}$ and Jin Guoc \\ School of Highway, Chang'an University, Xi'an, Shaanxi Province, China \\ alipaomian@163.com, b617546010@qq.com, c136309443@qq.com
}

\begin{abstract}
Keywords: road engineering; warm mixture asphalt; warm-mix agent; performance evaluation.
Abstract. Recommended dosage and type of warm mix agent widely used at present were investigated in order to determine the technical performance of warm-mixed asphalt and its mixture. The warm-mix agent's effect on asphalt performance were analyzed based on the three major indexes experiments of asphalt, and the road performance of the asphalt mixture is evaluated by high and low temperature test and water stability test. The results showed that the majority of warm-mix agent products can improve the high temperature performance of asphalt, and deteriorate the low temperature performance; the majority of warm-mix agent can cause decline in the low temperature performance, but have little impact on other indexes. The new product development should be aim at existing problems for improving design.
\end{abstract}

\section{Introduction}

At present, hot mixture asphalt(HMA) is commonly used in the construction of highway asphalt pavement in China. The production and construction process of HMA can consume a lot of energy, affect the environment and is harmful to construction workers' health, and it might cause the asphalt aging, because of the high temperature. Cold mixture asphalt has advantages in environmental protection and energy consumption, but its road performance is not stable, the construction quality is difficult to guarantee. So, how to combine the advantages of hot mixture asphalt and cold mixture asphalt to develop the warm mixture asphalt, which is a good performance of asphalt mixture, has always been the research direction in the field of road engineering. In this regard, scholars have carried out extensive researches, and achieved some results, but there are still many problems in the engineering application.

In order to promote the development and application of the warm mixture asphalt technology, and provide reference for the choice of warm-mix agent, this paper comprehensively investigated the type of warm-mix agent and their recommended dosage, and it analyzed the effect of warm-mix agent on performance, and determined the function of common warm-mix agent.

\section{Research and Application Status of Warm-mix Asphalt Agent}

Warm mixture asphalt was first developed by Shell company and Kolo-veidekk company in 1995, then the engineering application was carried out, and the results verified the good performance of warm mixture asphalt ${ }^{[1]}$. In 2003, the surface active platform warm-mix technology was first applied, and three major warm-mix technology systems were formally formed, including the viscosity reduction of the cementing material, asphalt foaming, and surface activity ${ }^{[2]}$. At present, warm-mix asphalt technology is matured applied abroad, and formed the relevant technical standards and quality evaluation system ${ }^{[3]}$.

In China, a series of warm-mix asphalt test road has been paved since 2006, and the studies about design methods of warm mixture asphalt has advanced the key control parameters, the standard of raw materials and construction technology of warm mixture asphalt[4]. Energy saving and emission reduction effect of quantitative analysis results showed that: warm mixture asphalt can save about $22.9 \% \sim 28.7 \%$ energy than hot mixture asphalt[5]. At present, most of the warm-mix agent products in engineering are imported. And since the products with independent intellectual property are in 
minority, the high price of the warm-mix agent limits the promotion and application of warm-mix asphalt technology.

\section{The Performance Evaluation of Warm-mix Agent}

In order to analyze the influence of the common warm-mix agent on the asphalt properties, the products of warm-mix agent and its optimum dosage were investigated, and the change law of the index of the warm-mix asphalt was determined by three major indexes test. The results are shown in Table 1.

Table 1 Test results of three indexes of warm mix asphalt

\begin{tabular}{|c|c|c|c|c|c|c|}
\hline $\begin{array}{l}\text { Warm-mix } \\
\text { agent }\end{array}$ & Base asphalt & $\begin{array}{c}\text { Recommended } \\
\text { dosage }\end{array}$ & $\begin{array}{c}\text { Change of } \\
\text { penetration } \\
{[\%]}\end{array}$ & $\begin{array}{c}\text { Change of } \\
\text { softening point } \\
{[\%]}\end{array}$ & $\begin{array}{c}\text { Change of } \\
\text { ductility } \\
{[\%]}\end{array}$ & $\begin{array}{c}\text { Temperatur } \\
\mathrm{e} \\
{\left[{ }^{\circ} \mathrm{C}\right]}\end{array}$ \\
\hline \multirow{6}{*}{ Sasobit } & Karamay70\# & $3.0 \%$ & $\downarrow 42.4$ & $\uparrow 62.0$ & $\downarrow 78.3$ & 10 \\
\hline & Shell 90\# & $3.0 \%$ & $\downarrow 34.8$ & $\uparrow 45.3$ & $\downarrow 70.3$ & 10 \\
\hline & $\begin{array}{l}\text { SBS Modified } \\
\text { Asphalt }\end{array}$ & $3.0 \%$ & $\downarrow 47.6$ & $\uparrow 4.3$ & $\downarrow 71.3$ & 5 \\
\hline & Rubber Asphalt & $4.0 \%$ & $\downarrow 25.0$ & $\uparrow 33.5$ & $\downarrow 73.9$ & 5 \\
\hline & $\begin{array}{l}\text { SBS Modified } \\
\text { Asphalt }\end{array}$ & $3.0 \%$ & $\downarrow 35.0$ & $\uparrow 13.3$ & $\downarrow 46.4$ & 5 \\
\hline & $\begin{array}{l}\text { SBS Modified } \\
\text { SK Asphalt }\end{array}$ & $3.0 \%$ & $\downarrow 17.0$ & $\uparrow 15.2$ & $\downarrow 24.7$ & 5 \\
\hline \multirow{4}{*}{ Sasowam } & AH 70\# & $3.0 \%$ & $\downarrow 45.5$ & $\uparrow 39.4$ & l & 15 \\
\hline & Esso 90\# & $3.0 \%$ & $\downarrow 37.7$ & $\uparrow 50.6$ & $\downarrow 71.5$ & 10 \\
\hline & Karamay70\# & $3.0 \%$ & $\downarrow 37.7$ & $\uparrow 49.7$ & $\downarrow 56.5$ & 10 \\
\hline & Shell 90\# & $3.0 \%$ & $\downarrow 28.1$ & $\uparrow 36.8$ & $\downarrow 63.9$ & 10 \\
\hline \multirow{2}{*}{ Evotherm } & Esso 90\# & $5.0 \%$ & $\downarrow 2.7$ & $\uparrow 7.2$ & $\uparrow 22.5$ & 10 \\
\hline & $\begin{array}{l}\text { SBS Modified } \\
\text { Asphalt }\end{array}$ & $5.0 \%$ & $\downarrow 3.6$ & $\uparrow 0.1$ & $\downarrow 0.5$ & 5 \\
\hline \multirow{3}{*}{ Aspha-Min } & AH 70\# & $3.0 \%$ & $\downarrow 16.3$ & $\uparrow 3.3$ & 1 & 15 \\
\hline & $\begin{array}{c}\text { SBS Modified } \\
\text { Asphalt }\end{array}$ & $4.0 \%$ & $\downarrow 19.7$ & $\uparrow 3.0$ & $\downarrow 77.9$ & 5 \\
\hline & Base asphalt $70 \#$ & $3.0 \%$ & $\downarrow 44.1$ & $\uparrow 48.4$ & 1 & 15 \\
\hline \multirow{4}{*}{ EC120 } & Base asphalt $70 \#$ & $3.5 \%$ & $\downarrow 39.7$ & $\uparrow 80.1$ & $\downarrow 24.7$ & 5 \\
\hline & $\begin{array}{l}\text { SBS Modified } \\
\text { Asphalt }\end{array}$ & $3.0 \%$ & $\downarrow 49.2$ & $\uparrow 9.7$ & $\downarrow 76.2$ & 5 \\
\hline & ES-70 & $3.0 \%$ & $\downarrow 36.7$ & $\uparrow 44.0$ & $\downarrow 69.6$ & 10 \\
\hline & PJ-130 & $3.0 \%$ & $\downarrow 53.1$ & $\uparrow 70.0$ & $\downarrow 36.7$ & 10 \\
\hline
\end{tabular}

Table1 shows that Sasobit can effectively reduce the asphalt penetration, and the average decline is $33.2 \%$. Evotherm has little influence on the penetration and the decline is only $2.7 \%-3.6 \%$. For Aspha-min, the average decline of asphalt penetration is $26.7 \%$, the effect is less than Sasobit. EC120 can significantly reduce the asphalt penetration, and the average decline is $44.68 \%$. The common warm-mix agent can make the penetration decreased, consistency becomes larger, and increase the anti-deformation ability. 
After using the Sasobit, the average increase of softening point of SBS modified asphalt is $12.6 \%$. For the EC120, the average increase is $50.95 \%$, among them, the increase of SBS modified asphalt is the smallest, which is 9.7\%. And Aspha-min and Evotherm's effect are very little. On the whole, the asphalt softening point is improved in different degrees by the common warm-mix asphalt, which indicates that the high temperature performance of asphalt can be improved by warm-mix agent.

When the Sasobit is used, the average decline of the ductility is $58.4 \%$, and the addition of the warm-mix agent greatly reduces the low temperature performance of asphalt. Using Evotherm, SBS modified asphalt's ductility decreased by $0.5 \%$, but the ductility of Esso $90 \#$ asphalt increased by $22.5 \%$. For the Aspha-min and EC120, the ductility of asphalt decreased significantly. On the whole, Evotherm has little effect on the low temperature performance of asphalt, Aspha-min, EC120 and Sasobit all make the low temperature performance degrade.

\section{The Performance Evaluation of Warm Mixture Asphalt}

The application effect of warm-mix agent need to evaluate by the pavement performance. So, making different types of warm-mix asphalt mixture, do some experiments to determined a series of indexes. Indexes including the dynamic stability, failure strain in the low temperature $\left(-10^{\circ} \mathrm{C}\right)$, failure stiffness modulus and intensity ratio of frozen and melted, they can be used for evaluate the pavement performance. The results are shown in Table 2.

Table 2 Test results of road performance of warm mixture asphalt

\begin{tabular}{|c|c|c|c|c|c|c|}
\hline $\begin{array}{l}\text { Warm-mi } \\
\mathrm{x} \text { agent }\end{array}$ & Base asphalt & $\begin{array}{l}\text { Recommended } \\
\text { dosage }\end{array}$ & $\begin{array}{l}\text { Change of } \\
\text { dynamic } \\
\text { stability } \\
{[\%]}\end{array}$ & $\begin{array}{c}\text { Change of } \\
\text { failure } \\
\text { strain } \\
{[\%]}\end{array}$ & $\begin{array}{l}\text { Change of } \\
\text { stiffness } \\
\text { modulus } \\
{[\%]}\end{array}$ & $\begin{array}{c}\text { Change of intensity } \\
\text { ratio of frozen and } \\
\text { melted } \\
{[\%]}\end{array}$ \\
\hline \multirow{8}{*}{ Sasobit } & Karamay70\# & $3.0 \%$ & $\uparrow 67.2$ & $\downarrow 7.6$ & $\uparrow 19.2$ & $\uparrow 4.3$ \\
\hline & $\begin{array}{l}\text { SBS Modified } \\
\text { Asphalt }\end{array}$ & $3.0 \%$ & $\uparrow 12.5$ & $\downarrow 22.8$ & $\uparrow 27.1$ & $\uparrow 2.0$ \\
\hline & Asphalt 70\# & $3.0 \%$ & $\uparrow 55.1$ & $\downarrow 2.0$ & $\uparrow 16.3$ & $\downarrow 0.1$ \\
\hline & $\mathrm{AR}$ & $3.0 \%$ & $\uparrow 81.2$ & $\downarrow 7.2$ & $\uparrow 11$ & $\uparrow 9.7$ \\
\hline & Panjin AH-90 & $3.0 \%$ & $\uparrow 30.2$ & $\uparrow 38.0$ & $\downarrow 17.8$ & $\uparrow 10.9$ \\
\hline & Taizhou 70\# & $3.0 \%$ & $\uparrow 96.1$ & $\uparrow 23.6$ & $\downarrow 17.8$ & $\begin{array}{l}\uparrow 0.1 \\
\end{array}$ \\
\hline & $\begin{array}{c}\text { Base asphalt } \\
70 \#\end{array}$ & $3.0 \%$ & - & $\downarrow 9.4$ & $\uparrow 24.8$ & - \\
\hline & Pen60/80 & $3.0 \%$ & 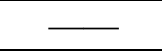 & $\downarrow 8.3$ & $\uparrow 6.1$ & - \\
\hline \multirow{4}{*}{ Evotherm } & Asphalt 70\# & $0.25 \%$ & $\downarrow 16.1$ & $\downarrow 1.6$ & $\uparrow 12.5$ & $\downarrow 4.8$ \\
\hline & $\mathrm{AR}$ & $0.3 \%$ & $\uparrow 0.9$ & $\downarrow 4.8$ & $\uparrow 4.7$ & $\uparrow 0.2$ \\
\hline & Pen60/80 & $0.3 \%$ & - & $\downarrow 0.3$ & $\uparrow 0.6$ & $\uparrow 2.4$ \\
\hline & SBR & $0.3 \%$ & $\uparrow 37.3$ & $\bar{C}$ & - & 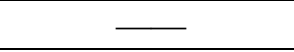 \\
\hline Aspha-mi & Taizhou 70\# & $0.3 \%$ & $\uparrow 53.9$ & $\uparrow 17.5$ & $\downarrow 9.6$ & $\downarrow 17.7$ \\
\hline \multirow{3}{*}{ EC120 } & Asphalt 70\# & $3.0 \%$ & $\uparrow 232.0$ & $\uparrow 10.9$ & $\downarrow 8.7$ & $\uparrow 6.2$ \\
\hline & $\begin{array}{l}\text { SBS Modified } \\
\text { Asphalt }\end{array}$ & $3.0 \%$ & $\uparrow 45.2$ & $\downarrow 0.5$ & $\uparrow 25.7$ & $\uparrow 4.1$ \\
\hline & ES-70 & $3.5 \%$ & $\uparrow 131.0$ & $\downarrow 9.7$ & $\uparrow 7.1$ & $\uparrow 17.3$ \\
\hline
\end{tabular}

Table2 shows that Sasobit can significantly improve the high temperature performance of asphalt mixture, and under the optimum dosage, the average increase of the dynamic stability is $74.9 \%$. For Evotherm, the dynamic stability of base asphalt mixture was decreased by $16.1 \%$, and the dynamic stability of SBR modified asphalt mixture was increased by $37.7 \%$. About EC120, the dynamic stability 
is increased between $45.2 \%$ and $232 \%$. Except the Evotherm, other warm-mix agents all increase the high temperature performance of the asphalt mixture.

The warm-mix agents' influence on the low temperature performance of asphalt mixture is related to the variety of base asphalt. the addition of warm-mix agent will have a negative effect on the most of asphalt mixture, but there are also some warm-mix agent can improve the low temperature performance of some asphalt mixture.

Using Sasobit and EC120 mixture, intensity ratio of frozen and melted of asphalt mixture slightly increased, the average increase was 5.5\% and 9.2\% respectively. Evotherm has little effect on this index. When Aspha-min was used, the tensile strength ratio was decreased by $17.7 \%$. In general, the effect of warm-mix agent on the water stability of mixture is relatively small.

\section{Conclusions}

Add the warm-mix agent to asphalt can make the penetration decreased, softening point rise. It is indicating that the commonly used warm-mix agents can improve the anti-deformation capacity of asphalt and high temperature performance.

Evotherm has little effect on the low temperature performance of asphalt, while Aspha-min, EC120 and Sasobit all make the low temperature performance fall. So the commonly used warm-mix agent have adverse effects on the low temperature performance of asphalt.

In addition to the Evotherm has little effect on the dynamic stability, the high temperature performance of the mixture can be improved by the most of the warm-mix agent, and the anti-rutting ability of the mixture is enhanced.

the effect of warm-mix agent on the low temperature performance of asphalt mixture is different. Most of the warm-mix agents have a negative effect on the low temperature performance. And the water stability of asphalt mixture is slightly improved by common warm-mix agents, but the effect is little.

\section{References}

[1] Zhifei Liu, Shaopeng Wu, Meizhu Chen. Status and Problems of Warm Mix Asphalt [J]. Journal of Wuhan University of Technology(in Chinese), 2009,31(4):170-173.

[2] Wenyuan Huang, Yongchun Qin. Application Status of Warm Mix Asphalt Technology at Domestic and Abroad [J]. Shanghai Highways, (in Chinese) 2008,(3):1-4.

[3] Graham C. Hurley, Brian D. Prowell. Evaluation of Evotherrn for use in warm mix asphalt[R]. NCAT Report06-02, 2006.

[4] Jian Wu, Yun Liang. Application of Warm-mix Asphalt in Cangling Tunnel of Taijin Highway [J]. Modern Transportation technology(in Chinese), 2008,5(3):9-13.

[5] Yongchun Qin, Songchang Huang, Jian Xu, Feng Li. Test and Analysis of Energy Saving and Emission Reduction of Warm Mixed Asphalt [J]. Highway Transportation Science and echnology(in Chinese), 2009,26(8):33-37 